\title{
Can combining economizers with improved filtration save energy and protect equipment in data centers?
}

\author{
Arman Shehabi ${ }^{\text {a,b }}$, Srirupa Ganguly ${ }^{\text {b }}$, Lara A. Gundel ${ }^{\text {b }}$, Arpad Horvath ${ }^{\text {a }}$, \\ Thomas W. Kirchstetter ${ }^{\mathrm{b}}$, Melissa M. Lunden ${ }^{\mathrm{b}}$, William Tschudi ${ }^{\mathrm{b}}$, \\ Ashok J. Gadgil ${ }^{\mathrm{a}, \mathrm{b}}$, William W Nazaroff ${ }^{\mathrm{a}, \mathrm{b}}{ }^{*}$ \\ ${ }^{a}$ Department of Civil and Environmental Engineering, \\ University of California, Berkeley, CA 94720-1710, USA \\ ${ }^{\mathrm{b}}$ Environmental Energy Technologies Division, Lawrence Berkeley \\ National Laboratory, Berkeley, CA 94720, USA
}

Abstract

Economizer use in data centers is an energy efficiency strategy that could significantly limit electricity demand in this rapidly growing economic sector. Widespread economizer implementation, however, has been hindered by potential equipment reliability concerns associated with exposing information technology equipment to particulate matter of outdoor origin. This study explores the feasibility of using economizers in data centers to save energy while controlling particle concentrations with high-quality air filtration. Physical and chemical properties of indoor and outdoor particles were analyzed at an operating northern California data center equipped with an economizer under varying levels of air filtration efficiency. Results show that when improved filtration is used in combination with an economizer, the indoor/outdoor concentration ratios for most measured particle types were similar to levels when using conventional filtration without economizers. An energy analysis of the data center reveals that, even during the summer months, chiller savings from economizer use greatly outweigh any increase in fan power associated with improved filtration. These findings indicate that economizer use combined with improved filtration could reduce data center energy demand while providing a level of protection from particles of outdoor origin similar to that observed with conventional design.

\footnotetext{
* Corresponding author information: Tel: +15106421040. E-mail address: nazaroff@ ce.berkeley.edu (W. Nazaroff)
} 
Keywords: Indoor air quality; particulate matter; hygroscopic salts; black carbon; equipment reliability; energy efficiency

\section{Introduction}

Data centers house electronic equipment that is integral to modern day information technology (IT). The operation of data center buildings in the United States consumes a substantial and rapidly increasing proportion of total national electricity demand. For example, in 2005, US data center operations required about 45 billion $\mathrm{kWh}$ of electricity, which was twice the amount used in 2000 and more than $1 \%$ of total US electricity demand (Koomey, 2007). Under a business-as-usual trajectory, data center electricity use in the US is projected to double in five years, although energy efficiency practices have been identified that could significantly reduce the rate of increase (Brown et al., 2007). One potentially important efficiency practice is the use of economizers, which provide large amounts of outside air for cooling internal heat loads during favorable weather conditions, thereby reducing the high air-conditioning energy demand associated with data center operation. Economizer implementation, however, has been hindered by perceived potential equipment reliability concerns associated with exposing IT equipment to outdoor particulate matter (PM) (Tschudi et al., 2004). Economizer use has been shown to increase particle concentrations relative to conventional non-economizer data center cooling design (Shehabi et al., 2008). Although the higher concentrations are still below most air quality guidelines, data center guidelines themselves vary widely (ASHRAE, 2009) and any increase in levels relative to conditions occurring under conventional practice may dissuade economizer implementation, especially given the strong emphasis in this sector on performance reliability.

This paper explores the feasibility of using economizers in data centers to save energy 
while simultaneously controlling indoor particle concentrations with improved air filtration. Time- and size-resolved particle concentration data were gathered at an operating northern California data center while using air filtration of varying levels of efficiency. Along with measuring the size- and time-resolved indoor and outdoor particle concentrations, chemical analysis of particulate sulfate, nitrate, chloride, and carbon was performed under each filter and economizer configuration. Metered electricity data were also gathered to compare overall operational energy use for each condition. Fan power requirements were calculated, using the mechanical design specifications of the data center, to disaggregate the potential increase in fan energy associated with improved filtration from the energy use associated with compressorbased cooling. The measured particle characteristics and energy use are evaluated to explore the potential energy savings associated with a shift from conventional cooling and filtration practices in data centers to a system with economizer use, to save energy, combined with improved filtration, to ensure protection of equipment from particle contamination.

\section{Methods}

\subsection{Experimental Design}

Particle concentrations were measured at a data center in Sunnyvale, CA during August, 2008. Real-time measurements were made and two- or three-day integrated filter-based samples were collected during 8-29 August for subsequent analysis. The mechanical system at this data center is designed with an economizer, allowing the amount of outside air entering the zone to be adjusted depending on outside temperature and humidity conditions. The amount of outside air entering the data center is controlled by an energy management and control system (EMCS). This data center was evaluated in a previous study (Shehabi et al., 2008), which presents details of the building layout and mechanical design. Briefly, economizer dampers within the air- 
handling units (AHU) modulate the ratio of outside air to return air that enters the AHU. Once in the AHU, this blend of outside and return air passes across a bank of filters, is thermally conditioned, and is then ducted to the data center zone for the purpose of removing heat generated by the racks of operating IT equipment. During the monitoring period of this study, the economizer system was manually controlled to be in an "economizer-off" mode from noon to 6:00 PM. In this condition, outside air accounts for only about $1 \%$ of the air entering the AHU with the rest being return air from the data center. During the remaining 18 hours of each day, the economizer system was set to an "economizer-on" mode, where all return air was exhausted from the building and the data center was cooled with $100 \%$ outside air, augmented as necessary with compressor-based air conditioning. When in economizer-on mode the data center airexchange rate reaches nearly 50 per hour. The hours of economizer activity were chosen to match typical temperature and humidity controlled economizer use in data centers during summer months at this northern California location.

Heating ventilation and air-conditioning (HVAC) filters with three different minimum efficiency reporting value (MERV) ratings were installed during the monitoring period. A higher MERV rating indicates greater particle-removal efficiency by the filter (ASHRAE, 1999). Immediately before monitoring began, new HVAC filters with a rating of MERV 7 were installed. MERV 7 filters are commonly used at this data center and previous studies have reported that the use of MERV 7 filters is consistent with normal industry practice (Brown et al., 2007). During other phases of the monitoring period, the MERV 7 filters were removed and replaced with more efficient MERV 14 filters, and later the MERV 14 filters were replaced with MERV 11 filters. All the filters are from a single manufacturer and represent commonly sold filter models within their respective efficiency category. Each filter type remained in place for 
approximately one week of operation.

\subsection{Real-Time Measurements}

Size resolved particle concentrations were measured using two Met-One 237B optical particle counters (OPC). These particle counters are capable of detecting particles within the range 0.3-5.0 $\mu \mathrm{m}$ optical diameter and categorizing the particle counts into different size bins, with an uncertainty of $\pm 20 \%$ in particle counts for each size bin. The fine particle mass concentration was estimated from these particle counts assuming a particle density of $1.5 \mathrm{~g} / \mathrm{cm}^{3}$ (Pitz et al., 2003) and using the method described in Shehabi et al. (2008). The indoor particle counter was placed on top of the server rack, with the intake tube sampling from a position in front of the servers. The outdoor particle counter was placed within the air handling unit (AHU) at the outside air intake, prior to any filtration, to monitor the outdoor particle concentration entering the AHUs that serve the data center. Measurements were taken for three-minute periods at 10-minute intervals. Each OPC would draw air at a rate of $2.8 \mathrm{~L} / \mathrm{min}$ for three minutes and then pause for seven minutes before beginning the next particle-counting cycle. The two OPCs used in this study were tested prior to the monitoring period to ensure that each particle counter produced similar results (less than $10 \%$ difference) under the same conditions.

Black carbon was measured using a Magee Scientific AE22 aethalometer. The chemical structure of black carbon, or soot, results in high electrical conductivity (Andreae and Gelencser, 2006) and has been associated with higher than usual failure rates of electronic equipment (Morawska et al., 2009). The aethalometer, which measures light beam attenuation by particles collected on a quartz filter tape with an uncertainty of $\pm 10 \%$, was programmed to calculate black carbon concentrations in one-minute intervals. The aethalometer was placed on the data center floor, with two lengths of $12.7 \mathrm{~mm}$ diameter $\times 8 \mathrm{~m}$ copper tubing to collect air from both inside 
and outside of the data center. Sample air traveling through the copper tubing first passed through a cyclone with a $\mathrm{PM}_{2.5}$ cutoff at a flow rate of $25 \mathrm{l} / \mathrm{min}$. A portion of this sample air then entered the aethalometer $(4.5 \mathrm{l} / \mathrm{min})$ while the rest was discarded. Automated 2-way solenoid values were used upstream of the aethalometer to switch between drawing air from the inside and outside tubing in 20-minutes intervals. For each 20 -minute interval, the average concentration from only the last 10 minutes was used to represent that period. Measurements from the first 10 minutes were excluded to ensure that sudden changes in relative humidity, which could occur when switching sample air locations, would not disturb the aethalometer measurements (LaRosa et al., 2002; Wallace, 2005).

\subsection{Filter-Based Particle Measurements}

Chemical constituents of indoor and outdoor particles were measured using two sets of sample filters, one for indoor and one for outdoor measurements. Each filter set consisted of four filter holders: two for teflon (Teflo, $25 \mathrm{~mm}$ diameter, $3.0 \mu \mathrm{m}$ pore size, Pall p/n R2PI025) and two for quartz filters (Pall 2500QT). The teflon filters were mounted in Savillex (teflon) filter-holders downsteam of honeycomb denuders (described below). The holders for the quartz filters were stainless steel with each holding two quartz filters in series. One sample filter set was placed on the data center floor and the other set was located in an adjacent auxiliary room with the inlet extending outdoors to a position in front of the AHU outside air intake. For each filter set, air was drawn through $12.7 \mathrm{~mm}$ diameter $\times 2 \mathrm{~m}$ of copper tubing. The air passed through a cyclone with a $\mathrm{PM}_{2.5}$ cutoff at a flowrate of $25 \mathrm{l} / \mathrm{min}$ before branching to the four filter holders. Automated 3-way solenoid values located downstream of the filters directed the air flow equally to one pair of filter holders (one teflon and one with two quartz filters in series) during the economizer-off periods (noon - 6:00 PM), and then switched to the other matched pair 
of identical filters during the economizer-on periods (6:00 PM-noon). Filters were collected and replaced at 2-3 day intervals. The split of sample airflow between teflon and quartz filters was controlled with needle valves and the airflow rates were measured for each filter set using a BIOS DryCal DC-2 calibrator after each sampling filter replacement. Additional filters were transported to the monitoring site but not used in the experiment to provide for blank correction during filter analysis.

Particulate matter was sampled on teflon filters to determine sulfate, nitrate, and chloride concentrations. These particles present a potential concern for data centers owing to the ability of PM containing water-soluble ionic salts to deliquesce at high relative humidity and thereby conductively bridge isolated elements on circuit boards (Weschler, 1991). Sulfate has been used previously to demonstrate current leakage attributable to particle deposition under conditions of high particle concentration and high humidity (Litvak et al., 2000). Each teflon filter used to collect sulfate, nitrate, and chloride was preceded by a glass honeycomb denuder. The denuder was coated in citric acid on one end and magnesium oxide on the other using a protocol adapted from an EPA method (Chow and Watson, 1998; Lunden et al., 2003); the purpose was to remove gas phase ammonia, nitric acid, and hydrochloric acid from the airstream before PM collection. A 47-mm cellulose filter and a 47-mm nylon filter were placed in series immediately downstream of each teflon filter to account for the volatilization of collected ammonium nitrate and ammonium chloride particles. The cellulose filters were impregnated with citric acid to collect ammonia while the slightly alkaline nature of nylon filters was used to collect nitric acid and hydrochloric acid.

The teflon and nylon filters were analyzed for anions using a protocol from IBM labs with an estimated $\pm 5 \%$ measurement uncertainty (Christensen, 1996). Each teflon filter was 
extracted by first pipetting $200 \mu \mathrm{l}$ of ethanol onto the filter surface (to overcome the hydrophobicity of teflon) and then placing the filter into a precleaned sealable Kapak $^{\mathrm{TM}}$ plastic bag containing $5.8 \mathrm{ml}$ of deionized water. The bags were heat-sealed and placed into an oven maintained at $60{ }^{\circ} \mathrm{C}$ for one hour. The bags were then sonicated before transferring the contents to an autosampler vial. The nylon filters were extracted similarly, except that the extraction solvent was the eluent used for ion chromatography $(2.7 \mathrm{mM}$ sodium carbonate and $0.3 \mathrm{mM}$ sodium bicarbonate). The extracts were analyzed by ion chromatography using a Dionex 2020 Ion Chromatograph utilizing an AS12A-series separatory and standard $4 \mathrm{~mm}$ guard column. The citric-acid impregnated cellulose filters were extracted in deionized water with sonication and then analyzed for ammonium using an ion-specific electrode. Mass concentrations of $\mathrm{PM}_{2.5}$ were gravimetrically measured on the teflon filters using a Sartorius SE-2 microbalance, with the filters being placed in a temperature and humidification equilibration chamber at $35-40 \% \mathrm{RH}$ for $24 \mathrm{~h}$ prior to weighing, pre- and post-loading. However, inductively coupled plasma (ICP) analysis confirmed the visual appearance of minute brass filings on some of the filters after sampling. Consequently, filter-based $\mathrm{PM}_{2.5}$ mass concentration measurements were deemed unreliable and are not reported here.

Particulate matter was collected on quartz filters to determine particle carbon levels. Condensed-phase organic pollutants may be a concern as they can contribute to the failure of data center equipment by promoting arcing between relay contacts, which results in increased contact erosion, or by forming polymeric films that can increase resistance on contact surfaces (Shields and Weschler, 1998). The carbon content of the particles collected on quartz filters was determined using thermal optical analysis (TOA), as described in Kirchstetter and Novakov (2007). The TOA method has an estimated $\pm 5 \%$ measurement uncertainty. Filters were heated 
at a constant rate of $40{ }^{\circ} \mathrm{C} / \mathrm{min}$ from 50 to $700{ }^{\circ} \mathrm{C}$ in a pure oxygen atmosphere. The carbon evolved from the filter was passed over a platinum-coated ceramic catalyst in an oxygenated atmosphere at $800{ }^{\circ} \mathrm{C}$, causing it to fully oxidize to $\mathrm{CO}_{2}$. The resulting $\mathrm{CO}_{2}$ was measured with a nondispersive infrared analyzer over the entire temperature range. The intensity of light transmitted through the sample was continuously monitored during analysis using a spectrometer to determine when the light-absorbing carbon evolved from the sample. The majority of organic carbon is expected to evolve from the quartz filter at a lower temperature than black carbon. In this study, all particulate carbon was classified as either organic or black, and carbon that evolved at temperatures above $400{ }^{\circ} \mathrm{C}$ was classified as black.

Each quartz filter sample consisted of two 25-mm diameter quartz filters in series. This tandem method is used to correct positive sampling artifacts caused by organic gases that sorb to the quartz filter matrix (Turpin et al., 1994; Kirchstetter et al., 2001), since both carbonaceous particles and sorbed organic gases can contribute to the measured carbon during TOA. While only the upstream filter collects particles, organic gases are assumed to sorb to saturation on both upstream and downstream filters. The amounts of organic gases collected on the two filters in series are assumed to be similar; hence, the difference in measured $\mathrm{CO}_{2}$ between the filters is assigned to carbon generated from particles. Prior to use, all of the quartz filters were baked at $800{ }^{\circ} \mathrm{C}$ for $6 \mathrm{~h}$ to remove any carbonaceous impurities.

\subsection{Energy Calculations}

A combination of measured and theoretical power consumption calculations was used to estimate the energy loads for the three HVAC filter types and two ventilation conditions evaluated in this study. Output from the main electricity meter monitoring the entire data center building was continuously gathered to observe fluctuations in overall power demand. Separate 
sub-metering was performed for all electricity leaving the uninterrupted power supply (UPS) units, which represents electricity exclusively used to operate the IT equipment in the data center, such as server, network, and storage devices. The difference between these two metered electricity values represents the power demand for all non-computer equipment in the data center, which primarily consists of the HVAC chiller and fans, as well as UPS losses, lighting, and auxiliary uses (Brown et al., 2007). Power use data were collected in five-minute increments from both the main facility meter and the UPS sub-meter. Increase in fan power associated with improved supply air filtration was estimated using fan curves specific to the HVAC design at the data center and standard fan laws (ASHRAE, 2005):

$$
P_{i}=\frac{Q_{s} p_{s}}{\eta_{m} \eta_{f} \eta_{d} \eta_{b}}
$$

In equation (1), $P_{i}$ is the input power to the supply fan, $Q_{s}$ is the supply airflow rate, and $p_{s}$ is the fan static pressure. The parameters $\eta_{m}, \eta_{f}, \eta_{d}$ and $\eta_{b}$ represent efficiencies for the motor, fan, variable frequency drive (VFD), and fan belts respectively. Input power to the fan for the baseline (MERV 7) filtration case was calculated from the building fan curves assuming a motor efficiency of 0.9, which is representative of large commercial HVAC systems (Fisk et al., 2002). The fan efficiency was calculated from the building fan curves and the VFD efficiency was estimated at 0.95 based on manufacturer specifications. The data center fans are direct drive, corresponding to a fan belt efficiency of 1. Assuming that the system efficiencies are constant under small changes in pressure, the input fan power is directly proportional to the fan static pressure. The increase in static pressure caused by more efficient HVAC filters was then used to estimate the corresponding increase in fan power associated with that filter type. Static pressure increase was estimated by adding the differences in the manufacturer's published initial resistance values for each filter type used in this study (Airguard, 2009) to the static pressure 
indicated by the building fan curves.

\section{Results and Discussion}

\subsection{Particle Concentrations}

Table 1 presents time-averaged particle mass concentrations, in the size range $0.3-2.0 \mu \mathrm{m}$ diameter, as measured with the OPCs at the Sunnyvale data center operating with different HVAC filter types. For each measurement period, both the indoor and outdoor mass concentrations are averaged separately for the hours with $100 \%$ outside air ventilation (economizer-on) and 1\% outside air ventilation (economizer-off). Previous analysis has shown that fine particle mass concentrations measured in data centers are primarily of outdoor origin (Shehabi et al., 2008). This finding allows the indoor/outdoor (I/O) ratio of particles to be interpreted as an indicator of the performance of the HVAC system in protecting the indoor air in the data center from particles of outdoor origin. The I/O ratios for the OPC measurements during economizer-on and economizer-off periods for the three HVAC filter types are presented in Figure 1 (upper left frame). Two key qualitative findings are as expected: (a) the I/O ratio is higher when the economizer is on compared to when it is off, and (b) increased filter MERV ratings result in reduced I/O ratios. A key quantitative result illustrated in this figure is that the I/O ratio for the MERV 14 filters when the economizer is on is similar to the I/O ratio for the conventional MERV 7 filters when the economizer is off. In other words, this evidence suggests that a data center with an economizer using MERV 14 filters can expect similar indoor fineparticle mass concentrations to those for a conventional non-economizer data center using MERV 7 filters.

Indoor and outdoor concentrations of sulfate, nitrate, and chloride ions associated with airborne particles are presented in Table 2 and the ratios are depicted in Figure 2. Sulfate- 
bearing particles tend to penetrate into the data center and persist with a higher $\mathrm{I} / \mathrm{O}$ proportion than the PM fine-particle mass concentration measured by optical particle counting.

Qualitatively, such a finding might be expected, since atmospheric sulfate is concentrated in the submicron portion of the accumulation mode (Milford and Davidson, 1987) and is consequently expected to exhibit a relatively high indoor proportion of outdoor particles (Riley et al., 2002). Furthermore, while sulfate in particles is thermodynamically stable, PM measured by the OPCs may include particles that volatilize once indoors, contributing to a lower I/O ratio. These results highlight an important point: if sulfate is a primary particle constituent of concern, then OPCs with the particle-size limitations used in this study may not be an ideal proxy for estimating the proportion of potentially harmful particles present in a data center. However, for sulfate, as for OPC-determined fine-particle mass, the MERV 14 filters when the economizer is on yield comparable I/O ratios as the case with MERV 7 filters when the economizer is off.

The I/O ratios measured for particulate nitrate, displayed in Figure 2, are much lower than the counterpart sulfate ratios under most conditions. Nitrate ratios can be influenced by gasto-particle conversion processes that occur inside the data center. Ammonium nitrate particles can easily shift between the condensed phase and their gaseous constituents with changes in temperature or in the concentrations of gaseous constituents (Lunden et al., 2003). Table 3 shows the average indoor and outdoor temperatures measured at the data center. Indoor temperatures tended to be warmer than outdoor temperatures during the economizer-on period and cooler than outdoors during the economizer-off period but to extents that varied among the different filtration periods. The differences between the indoor and outdoor temperatures could have affected the extent of nitrate volatilization and formation. The gas-phase constituents of ammonium nitrate, specifically ammonia and nitric acid, can also be lost by interactions with 
indoor surfaces. The loss of these gaseous constituents, particularly nitric acid, to indoor surfaces is another important driver influencing the loss of indoor particulate nitrate. Indoor sources of gaseous constituents might have also influenced the measured nitrate concentrations and corresponding I/O ratios. Although cleaning product use is typically minimal in data centers, one interior wall of the Sunnyvale data center is glass that is routinely cleaned with an ammonia-based product. The consequent indoor release of ammonia may have influenced the measured I/O nitrate ratios by shifting the balance between the gaseous constituents - ammonia and nitric acid — and particulate ammonium nitrate.

The measured particulate chloride concentrations, shown in Table 2, are similar in magnitude to previous chloride $\mathrm{PM}_{2.5}$ measurements from the California coast and significantly higher than particulate chloride concentrations measured in other regions of California (Chow et al., 1996). Sodium chloride from marine aerosol is primarily found in coarse particles, but can react with acidic gases and ammonia to form submicron particulate ammonium chloride (Harrison and Pio, 1983). The Sunnyvale data center is located near the San Francisco bay and less than $2 \mathrm{~km}$ from a wastewater treatment plant and numerous salt ponds, all of which may have contributed to the relatively high particulate chloride concentrations measured. Ammonium chloride is similar in volatility to ammonium nitrate (Pio and Harrison, 1987). Consequently, particulate ammonium chloride concentrations can be influenced by temperature and by the concentrations of the gaseous constituents, ammonia and hydrochloric acid. Table 2 shows that outdoor particulate chloride is consistently lower during the economizer-off periods than when the economizer is on. This finding may reflect warmer temperatures during the afternoon hours, when the economizer is off, causing these thermodynamically unstable particles to volatilize into their gaseous constituents. Figure 2 shows minimal change in the particulate chloride I/O ratio 
with improved HVAC filter efficiency. Given the large number of data centers located in coastal regions (Brown et al., 2007), the potential impact of particulate chloride on IT equipment reliability warrants further investigation.

Table 4 shows average concentrations for carbonaceous particles measured under each filter condition, again sorted between economizer-on and economizer-off periods. The quartzfilter-based black carbon measurements provide similar I/O ratios to the aethalometer black carbon measurements, although the absolute values for the aethalometer are somewhat lower (the mean ratio of aethalometer to quartz-filter determination for black carbon for the different filter/economizer configurations is 0.65 ). The black carbon $\mathrm{I} / \mathrm{O}$ ratio trends are similar to those observed for the OPC particle measurements. Improved filtration reduces the black carbon I/O ratio, so that the MERV $14 \mathrm{I} / \mathrm{O}$ ratio during economizer-on periods is comparable to that for MERV 7 filtration during economizer-off periods (Figure 1). However, across all filter types and both economizer modes, the I/O ratio of black carbon is greater than that indicated by the OPC data. The black carbon I/O ratios correspond closely to the ratios measured for sulfate under most conditions. Similar I/O ratios for sulfate and black carbon might be expected, since both are thermodynamically stable and both particle types can be dominated by the $0.1-1 \mu \mathrm{m}$ size range (Seinfeld and Pandis, 2006), which are the most difficult to remove by fibrous filtration (Hinds, 1998). However, during the MERV 7 economizer-on period, the black carbon I/O ratios determined by both measurement methods are near unity and significantly higher than the corresponding sulfate ratios. A contributing factor to this observation might be the measurement uncertainty associated with the low outdoor black carbon concentrations during the MERV 7, economizer-on, monitoring period (Table 4).

The results for total carbon (Table 4) do not show a clear trend with increasing HVAC 
filter efficiency or economizer activity. Measurements of total carbon might have been affected by indoor gaseous emissions of semivolatile (SVOCs) or volatile organic compounds (VOCs). These chemical classes may have significant indoor sources in data centers, such as the constituents of the large amounts of plastics associated with the IT equipment and building materials. High concentrations of VOCs have been measured in data centers relative to other building types and VOC concentrations have been observed to be high in data centers with minimal ventilation, indicating the presence of significant internal sources (Shields et al., 1996).

Except for total carbon and chloride, Tables 1, 2, and 4 show significantly reduced indoor concentrations for all measured species with the MERV 14 filters installed as compared with the results for MERV 7 and MERV 11 filters. This observation is partly attributable to the lower outdoor concentrations during the MERV 14 monitoring period. For quality assurance, the outdoor total PM concentrations measured in this study were compared to regionally available outdoor $\mathrm{PM}_{2.5}$ particle concentration data reported by the Bay Area Air Quality Management District (BAAQMD) during these measurement periods (BAAQMD, 2009). The BAAQMD data represent measurements from a sampling site approximately $25 \mathrm{~km}$ away from the Sunnyvale data center. A decrease in outdoor concentrations during the MERV 14 sampling period is observed in both data sets, indicating that the change in outdoor particle concentration is a consequence of changes in ambient conditions, e.g. because of shifting meteorological factors, rather than anything specific to the experimental conditions of this study. A comparison of the measured outdoor concentrations and the BAAQMD data can be seen in Figure 3.

Scrutiny of Table 1 indicates that, within each measurement period, the OPC-determined outdoor particle concentrations were consistently higher when the economizer was operating (6:00 PM to noon) compared to the hours when the economizer was off (noon to 6:00 PM). This 
finding may result from several factors. The economizers are active during nighttime hours, when the mixing height of the atmosphere is generally lower, resulting in increases in ambient particle concentrations associated with proximate ground-level emissions (Seinfeld and Pandis, 2006). Also, the economizers are active during morning commute hours, when nearby emissions from vehicular traffic are expected to be high. The close proximity of the Sunnyvale data center's outside air intake to a heavily trafficked freeway may have contributed to these higher outdoor particle concentrations during economizer-on periods. The proximity of the study site to a freeway may also account for the rapid changes in outdoor particle concentrations observed at the data center during some economizer-on periods that are not seen in the BAAQMD data. 3.2 Energy Use

Table 5 presents the average total building power and the average power specific to IT equipment for each filter and economizer operating condition. Average power values are separated into the two time categories representing the economizer-on (6:00 PM - noon) and economizer-off (noon - 6:00 PM) periods for each filter configuration, except for the first data line presented in Table 5 for which the economizer was off during all times. As expected, the average IT loads are nearly constant, whereas the average load for the entire building decreases for the periods when the economizer is active. A smaller decrease in the main building load is also observed during the period when the economizer remained off. The decrease is probably attributable to lower outdoor temperatures, which would affect the amount of cooling required. Reduced lighting and other auxiliary demand during the evening and early morning hours when few occupants are in the building also may contribute to the observed difference. Cumulative probability distributions of the estimated non-IT power use for the economizer-on and economizer-off periods for each filter type are presented in Figure 4. Lower power demand 
during the economizer-on periods can be attributed primarily to reduced chiller operation. After adjusting for the $35 \mathrm{~kW}$ difference during the configuration when the economizer was off for both time categories, economizer savings can be estimated from the differences between the nonIT power use during each filter and economizer configuration. Applying this method to the power values in Table 5, the estimated average power savings associated with economizer use for the building were 107, 84, and $108 \mathrm{~kW}$ for the MERV 7, 11, 14 filter cases, respectively.

The lower savings during the MERV 11 period can be attributed to higher outdoor temperatures during that period, as shown in Table 3. The higher ambient temperatures decreased the number of hours during which the chiller was completely shut off. When the economizer is active, the system operates in either "full" or "partial" economizer mode. During full-mode operation, the outdoor temperature is below the supply air set point and no chiller power is required. When the outdoor temperature is above the supply air set point, but below the return air temperature, the system operates in partial economizer mode, during which the chiller is active, but at a reduced level compared to when the economizer is off.

The economizer-on non-IT power values for all three filter conditions presented in Figure 4 show two distinct distributions, which represent conditions during full and partial economizer modes. During the full economizer mode, the non-IT power consumption is reduced to approximately $150 \mathrm{~kW}$; this level is indicative of the base building power demand when the chiller is off. During the partial economizer mode, the building power load shifts to about 300$400 \mathrm{~kW}$. A subtle bimodal distribution can also be seen in the economizer-off values, a result of differences in afternoon temperatures between different days within the same measurement period. Evidence in Figure 4 reveals that the power savings observed in August is primarily attributable to periods when the economizer is in partial operation. During the MERV 11 
measurements, full economizer operation accounted for less than $10 \%$ of the economizer-on period. Economizer savings can be expected to be much larger, possibly more than double, during cooler months when the chiller can be completely off for longer periods.

Improved filtration might be associated with an energy penalty from higher fan power to overcome larger pressure drops. However, estimates indicate that fan power increases would be relatively minor. Building design fan curves indicate a total supply fan power demand of $64 \mathrm{~kW}$ during the baseline (MERV 7) filter condition. Supply fan power with the MERV 11 and 14 filters is calculated to increase to 67 and $70 \mathrm{~kW}$, respectively. Hence, the MERV 14 filters are expected to increase fan power by about $10 \%$. However, the absolute increase of $6 \mathrm{~kW}$ is much smaller than the $\sim 100 \mathrm{~kW}$ of expected chiller power savings during economizer use.

Furthermore, the increase in fan power is constant throughout the year whereas chiller savings during economizer use would be expected to increase during cooler periods relative to the August period studied here.

\section{Conclusion}

In conventional practice, economizers are often not implemented in data centers. A key reason is to limit the exposure of IT equipment to particles of outdoor origin. This aspect of data center design contributes to their high rate of energy use. The research reported here shows that economizer use combined with high-quality particle filtration can reduce data center power demand while simultaneously maintaining indoor particle levels similar to those using conventional (non-economizer) ventilation-system design and operation. Specifically, for most of the particle types measured in this study, when MERV 14 filters are used along with economizers, the I/O ratio is near levels that occur when using conventional MERV 7 filters without economizers. Energy analysis of the data center investigated in this study revealed that, 
even during a warm summer month (August) in northern California, chiller energy savings from economizer use greatly outweighed the increase in fan energy associated with improved filtration.

Investigating economizer use combined with improved filtration for other climates and during other seasons is needed to generalize the findings from this case study to a larger scale. Future work should also explore whether the protection provided by improved filtration is necessary to ensure IT equipment reliability. The particle concentrations measured at this site during economizer use with conventional MERV 7 filters, while higher than concentrations during non-economizer periods, were still below many IT equipment and data center guidelines. A more detailed understanding of how particle concentrations might adversely influence equipment reliability may obviate the need for improved filtration and the associated increase in fan energy and material cost associated with this protective measure. However, even without such understanding, the results reported here indicate that improved filtration is a viable mitigation alternative. High quality filtration can be combined with economizer use to simultaneously protect electronic equipment from outdoor particles while achieving significant energy savings in the operation of data centers.

\section{Acknowledgments}

We thank Benjamin Chu, Dennis DiBartolomeo, Ray Dod, Michael Lough-Stevens, and Douglas Sullivan for their contributions to developing the experimental apparatus and performing on-site monitoring, and Dale Christensen at IBM for conducting the ion chromatography analysis. We thank David Shroyer, Cameron Smith, Rudy Tajalle, Richard Turner, and the rest of the data center staff for their generous cooperation. This project was funded by Pacific Gas \& Electric and by the University of California Energy Institute, California 
Studies Grant Program. Most of the work was performed at LBNL under the U.S. Department of Energy Contract No. DE-AC02-05CH11231.

\section{References}

Airguard, 2009. New product cut sheets. www.airguard.com/new.html. Accessed January 2009

Andreae, M.O., Gelencser, A., 2006, Black carbon or brown carbon? The nature of lightabsorbing carbonaceous aerosols. Atmospheric Chemistry and Physics 6, 3131-3148.

ASHRAE, 1999. Method of testing general ventilation air-cleaning devices for removal efficiency by particle size. ANSI/ASHRAE Standard 52.2-1999. American Society of Heating, Refrigerating, and Air-Conditioning Engineers, Inc., Atlanta, GA.

ASHRAE, 2005. ASHRAE Handbook, HVAC Systems and Equipment. American Society of Heating, Refrigerating, and Air Conditioning Engineers, Atlanta, GA.

ASHRAE, 2009. Particulate and gaseous contamination in datacom environments. American Society of Heating, Refrigerating, and Air-Conditioning Engineers, Inc., Atlanta, GA.

BAAQMD, 2009. Forecasting and data analysis, Bay Area Air Quality Management District. www.baaqmd.gov. Accessed January 2009.

Brown, R., Masanet, E., Nordman, B., Tschudi, B., Shehabi, A., Stanley, J., Koomey, J., Sartor, D., Chan, P., Loper, J., Capana, S., Hedman, B., Duff, R., Haines, E., Sass, D., Fanara, A., 2007. Report to Congress on server and data center energy efficiency: Public Law 109-431. Report LBNL-363E, Lawrence Berkeley National Laboratory, Berkeley, CA.

Chow, J.C., Watson, J.G., 1998. Guideline on speciated particulate monitoring. Report prepared for US Environmental Protection Agency, Research Triangle Park, NC, by Desert Research Institute, Reno, NV.

Chow, J.C., Watson, J.G., Lu, Z., Lowenthal, D.H., Frazier, C.A., Solomon, P.A., Thuillier, R.H., Magliano, K., 1996. Descriptive analysis of $\mathrm{PM}_{2.5}$ and $\mathrm{PM}_{10}$ at regionally representative locations during SJVAQS/AUSPEX. Atmospheric Environment 30, 2079_ 2112.

Christensen, D., 1996. Anionic analysis by ion chromatography. IBM unclassified report 
20260.01, International Business Machines Corporation, Rochester, MN

Fisk, W.J., Faulkner, D., Palonen, J., Seppanen, O., 2002. Performance and costs of particle air filtration technologies. Indoor Air 12, 223-234.

Harrison, R.M., Pio, C.A., 1983. Size-differentiated composition of inorganic atmospheric aerosols of both marine and polluted continental origin. Atmospheric Environment 17, 17331738.

Hinds, W.C., 1998. Aerosol Technology: Properties, Behavior, and Measurement of Airborne Particles. $2^{\text {nd }}$ edition, Wiley, New York.

Kirchstetter, T.W., Novakov, T., 2007. Controlled generation of black carbon particles from a diffusion flame and applications in evaluating black carbon measurement methods. Atmospheric Environment 41, 1874-1888.

Kirchstetter, T.W., Corrigan, C.E., and Novakov, T., 2001. Laboratory and field investigation of the adsorption of gaseous organic compounds onto quartz filters. Atmospheric Environment $35,1663-1671$.

Koomey, J., 2007. Estimating total power consumption by servers in the U.S. and the world. enterprise.amd.com/Downloads/svrpwrusecompletefinal.pdf.

LaRosa, L.B., Buckley, T.J., Wallace, L.A., 2002. Real-time indoor and outdoor measurements of black carbon in an occupied house: an examination of sources. Journal of the Air and Waste Management Association 52, 41-49.

Litvak, A., Gadgil, A.J., Fisk, W.J., 2000. Hygroscopic fine mode particle deposition on electronic circuits and resulting degradation of circuit performance: an experimental study. Indoor Air 10, 47-56.

Lunden, M.M., Revzan, K.L., Fischer, M.L., Thatcher, T.L., Littlejohn, D., Hering, S.V., Brown, N.J., 2003. The transformation of outdoor ammonium nitrate aerosols in the indoor environment. Atmospheric Environment 37, 5633-5644.

Milford, J.B., Davidson, C.I., 1987. The sizes of particulate sulfate and nitrate in the atmosphere - a review. JAPCA - The International Journal of Air Pollution Control and Hazardous Waste Management 37, 125-134. 
Morawska, L., Jamriska, M., Guo, H., Jayaratne, E.R., Cao, M., Summerville, S., 2009. Variation in indoor particle number and $\mathrm{PM}_{2.5}$ concentrations in a radio station surrounded by busy roads before and after an upgrade of the HVAC system. Building and Environment 44, 76-84.

Pitz, M., Cyrys, J., Karg, E., Wiedensohler, A., Wichmann, H.E., Heinrich, J., 2003. Variability of apparent particle density of an urban aerosol. Environmental Science \& Technology 37 , 4336-4342.

Pio, C.A., Harrison, R.M., 1987. The equilibrium of ammonium chloride aerosol with gaseous hydrochloric acid and ammonia under tropospheric conditions. Atmospheric Environment 21, 1243-1246.

Riley, W.J., McKone, T.E., Lai, A.C.K., Nazaroff, W.W., 2002. Indoor particulate matter of outdoor origin: importance of size-dependent removal mechanisms. Environmental Science \& Technology 36, 200-207.

Seinfeld, J.H., Pandis, S.N., 2006. Atmospheric Chemistry and Physics: From Air Pollution to Climate Change. $2^{\text {nd }}$ edition. Wiley, New York.

Shehabi, A., Horvath, A., Tschudi, W., Gadgil, A.J., Nazaroff, W.W., 2008. Particle concentrations in data centers. Atmospheric Environment 42, 5978-5990.

Shields H.C., Fleischer D.M., Weschler C.J., 1996. Comparisons among VOCs measured in three types of US commercial buildings with different occupant densities. Indoor Air 6, 2-17.

Shields, H.C., Weschler, C.J., 1998. Are indoor air pollutants threatening the reliability of your electronic equipment? Heating/Piping/Air Conditioning Engineering 70(5), 46-54.

Tschudi, W., Xu, T., Sartor, D., Nordman, B., Koomey, J., Sezgen, O., 2004. Energy efficient data centers. Report LBNL-54163, Lawrence Berkeley National Laboratory, Berkeley, CA.

Turpin, B.J., Huntzicker, J.J., Hering, S.V., 1994. Investigation of organic aerosol sampling artifacts in the Los Angeles basin. Atmospheric Environment 28, 3061-3071.

Wallace, L., 2005. Real-time measurements of black carbon indoors and outdoors: a comparison of the photoelectric aerosol sensor and the aethalometer. Aerosol Science and Technology 39, 1015-1025. 
Weschler, C.J., 1991. Predictions of benefits and costs derived from improving indoor air quality in telephone switching offices. Indoor Air 1, 65-78.

\section{Figure Captions}

Figure 1. Indoor/outdoor concentration ratios for OPC-measured particles and carbonaceous particles, sorted by HVAC filter type and economizer activity. *Represents aethalometer black carbon measurements.

Figure 2. Indoor/outdoor concentration ratios for particulate sulfate, nitrate, and chloride, sorted by HVAC filter type and economizer activity.

Figure 3. Measured time-dependent indoor and outdoor particle mass concentrations over a 24hour period for each filter configuration. Concentrations represent particles 0.3-2.0 $\mu \mathrm{m}$ in diameter. Upper right graph represents a period when the economizer was inactive for all 24 hours. For the other three graphs, the economizer was inactive approximately between the hours of noon and 6:00 PM and active during the remaining hours. Also indicated are $\mathrm{PM}_{2.5}$ measurements from the Bay Area Air Quality Management District (BAAQMD) at a sampling site approximately $25 \mathrm{~km}$ from the data center.

Figure 4. Cumulative probability distributions of estimated non-IT power use for the economizer-on and economizer-off periods for each filter type. Economizer-off values have been adjusted for the $35 \mathrm{~kW}$ difference measured when the economizer was off for both time categories. Results indicate an average power savings of 107, 84, and $108 \mathrm{~kW}$ for economizer use for the MERV 7, 11, 14 filter conditions, respectively. 


\section{Tables}

Table 1. Average indoor and outdoor concentrations of OPC-measured particles, sorted by economizer activity and filtration efficiency rating.

\begin{tabular}{ccccc} 
HVAC & \multicolumn{4}{l}{ OPC PM $(0.3-2.0 \mu \mathrm{m})\left(\mu \mathrm{g} \mathrm{m}^{-3}\right)$} \\
\cline { 2 - 5 } MERV & \multicolumn{2}{l}{ Economizer ON } & \multicolumn{2}{l}{ Economizer OFF } \\
rating & Outdoor & Indoor & Outdoor & Indoor \\
\hline 7 & 10.2 & 2.5 & 5.3 & 0.43 \\
11 & 13.2 & 2.3 & 6.5 & 0.38 \\
14 & 3.3 & 0.22 & 0.85 & 0.03
\end{tabular}

Table 2. Average indoor and outdoor filter-based particulate sulfate, nitrate, and chloride concentrations, sorted by economizer activity and filtration efficiency rating.

\begin{tabular}{|c|c|c|c|c|c|c|c|c|c|c|c|c|}
\hline \multirow{3}{*}{$\begin{array}{l}\text { HVAC } \\
\text { MERV } \\
\text { rating }\end{array}$} & \multicolumn{4}{|c|}{ Sulfate $(\leq 2.5 \mu \mathrm{m})\left(\mu \mathrm{g} \mathrm{m}^{-3}\right)$} & \multicolumn{4}{|c|}{ Nitrate $(\leq 2.5 \mu \mathrm{m})\left(\mu \mathrm{g} \mathrm{m}^{-3}\right)$} & \multicolumn{4}{|c|}{ Chloride $(\leq 2.5 \mu \mathrm{m})\left(\mu \mathrm{g} \mathrm{m}^{-3}\right)$} \\
\hline & \multicolumn{2}{|c|}{ Economizer ON } & \multicolumn{2}{|c|}{ Economizer OFF } & \multicolumn{2}{|c|}{ Economizer ON } & \multicolumn{2}{|c|}{ Economizer OFF } & \multicolumn{2}{|c|}{ Economizer ON } & \multicolumn{2}{|c|}{ Economizer OFF } \\
\hline & Outdoor & Indoor & Outdoor & Indoor & Outdoor & Indoor & Outdoor & Indoor & Outdoor & Indoor & Outdoor & Indoor \\
\hline 7 & 1.8 & 1.4 & 1.5 & 0.56 & 1.1 & 0.48 & 1.2 & 0.11 & 0.75 & 0.23 & 0.13 & 0.09 \\
\hline 11 & 1.2 & 0.92 & 1.6 & 0.37 & 1.4 & 0.60 & 2.5 & 0.38 & 1.3 & 0.28 & 0.38 & 0.12 \\
\hline 14 & 0.94 & 0.37 & 0.35 & 0.03 & 0.20 & 0.04 & 0.16 & 0.04 & 0.12 & 0.03 & 0.19 & 0.15 \\
\hline
\end{tabular}

Table 3. Average outdoor and indoor air temperatures $\left({ }^{\circ} \mathrm{C}\right)$ during the August 2008 study, sorted by filter type and according to whether the economizer was "on" or "off."

\begin{tabular}{crrrr}
\multirow{2}{*}{$\begin{array}{l}\text { HVAC MERV } \\
\text { rating }\end{array}$} & \multicolumn{3}{c}{ Outdoor } & \multicolumn{3}{c}{ Indoor } \\
\cline { 2 - 5 } & ON & OFF & ON & OFF \\
\hline 7 & 18.0 & 30.4 & 21.4 & 21.4 \\
11 & 21.2 & 33.6 & 22.1 & 22.1 \\
14 & 17.5 & 26.2 & 22.2 & 22.2
\end{tabular}


Table 4. Average measured indoor and outdoor carbonaceous particle concentrations, sorted by economizer activity and filter type.

\begin{tabular}{|c|c|c|c|c|c|c|c|c|c|c|c|c|}
\hline \multirow{3}{*}{$\begin{array}{l}\text { HVAC } \\
\text { MERV } \\
\text { rating }\end{array}$} & \multicolumn{4}{|c|}{ Total carbon $(\leq 2.5 \mu \mathrm{m})\left(\mu \mathrm{g} \mathrm{C} \mathrm{m}^{-3}\right)$} & \multicolumn{4}{|c|}{ Black carbon $(\leq 2.5 \mu \mathrm{m})\left(\mu \mathrm{g} \mathrm{C} \mathrm{m}^{-3}\right)$} & \multicolumn{4}{|c|}{ Black carbon $*(\leq 2.5 \mu \mathrm{m})\left(\mu \mathrm{g} \mathrm{C} \mathrm{m}^{-3}\right)$} \\
\hline & \multicolumn{2}{|c|}{ Economizer ON } & \multicolumn{2}{|c|}{ Economizer OFF } & \multicolumn{2}{|c|}{ Economizer ON } & \multicolumn{2}{|c|}{ Economizer OFF } & \multicolumn{2}{|c|}{ Economizer ON } & \multicolumn{2}{|c|}{ Economizer OFF } \\
\hline & Outdoor & Indoor & Outdoor & Indoor & Outdoor & Indoor & Outdoor & Indoor & Outdoor & Indoor & Outdoor & Indoor \\
\hline 7 & 1.4 & 1.1 & 1.3 & 0.70 & 0.34 & 0.32 & 0.32 & 0.18 & 0.15 & 0.15 & 0.16 & 0.05 \\
\hline 11 & 2.9 & 2.1 & 4.0 & 1.1 & 0.76 & 0.57 & 0.91 & 0.20 & 0.93 & 0.67 & 0.65 & 0.15 \\
\hline 14 & 0.62 & 0.60 & 0.65 & 1.5 & 0.26 & 0.13 & 0.28 & 0.05 & 0.20 & 0.08 & 0.17 & 0.01 \\
\hline
\end{tabular}

Table 5. Measurement time periods, average total building power, and the average power specific to IT equipment for each filter type.

\begin{tabular}{|c|c|c|c|c|c|c|c|c|}
\hline \multirow{2}{*}{\multicolumn{2}{|c|}{ Measurement period (2008) }} & \multirow{3}{*}{$\begin{array}{l}\text { HVAC } \\
\text { MERV } \\
\text { rating }\end{array}$} & \multicolumn{6}{|c|}{ Power use measurement results (kW) } \\
\hline & & & \multirow{2}{*}{$\begin{array}{l}\text { Total building } \\
18: 00-12: 00\end{array}$} & \multirow[b]{2}{*}{$12: 00-18: 00$} & \multicolumn{2}{|c|}{ Computer and other IT } & \multirow{2}{*}{$\begin{array}{l}\text { Non IT use } \\
\text { 18:00-12:00 }\end{array}$} & \multirow[b]{2}{*}{$12: 00-18: 00$} \\
\hline Start & End & & & & $18: 00-12: 00$ & $12: 00-18: 00$ & & \\
\hline 12 Aug 0:00 & 14 Aug 0:00 & $7 *$ & $1047 *$ & 1081 & 680 & 680 & $367 *$ & 402 \\
\hline 8 Aug 13:00 & 11 Aug 12:30 & 7 & 937 & 1078 & 681 & 679 & 256 & 398 \\
\hline 25 Aug 15:00 & 29 Aug 13:00 & 11 & 987 & 1105 & 687 & 686 & 299 & 418 \\
\hline 18 Aug 19:30 & 20 Aug 11:30 & 14 & 930 & 1071 & 690 & 688 & 240 & 383 \\
\hline
\end{tabular}


Figure 1
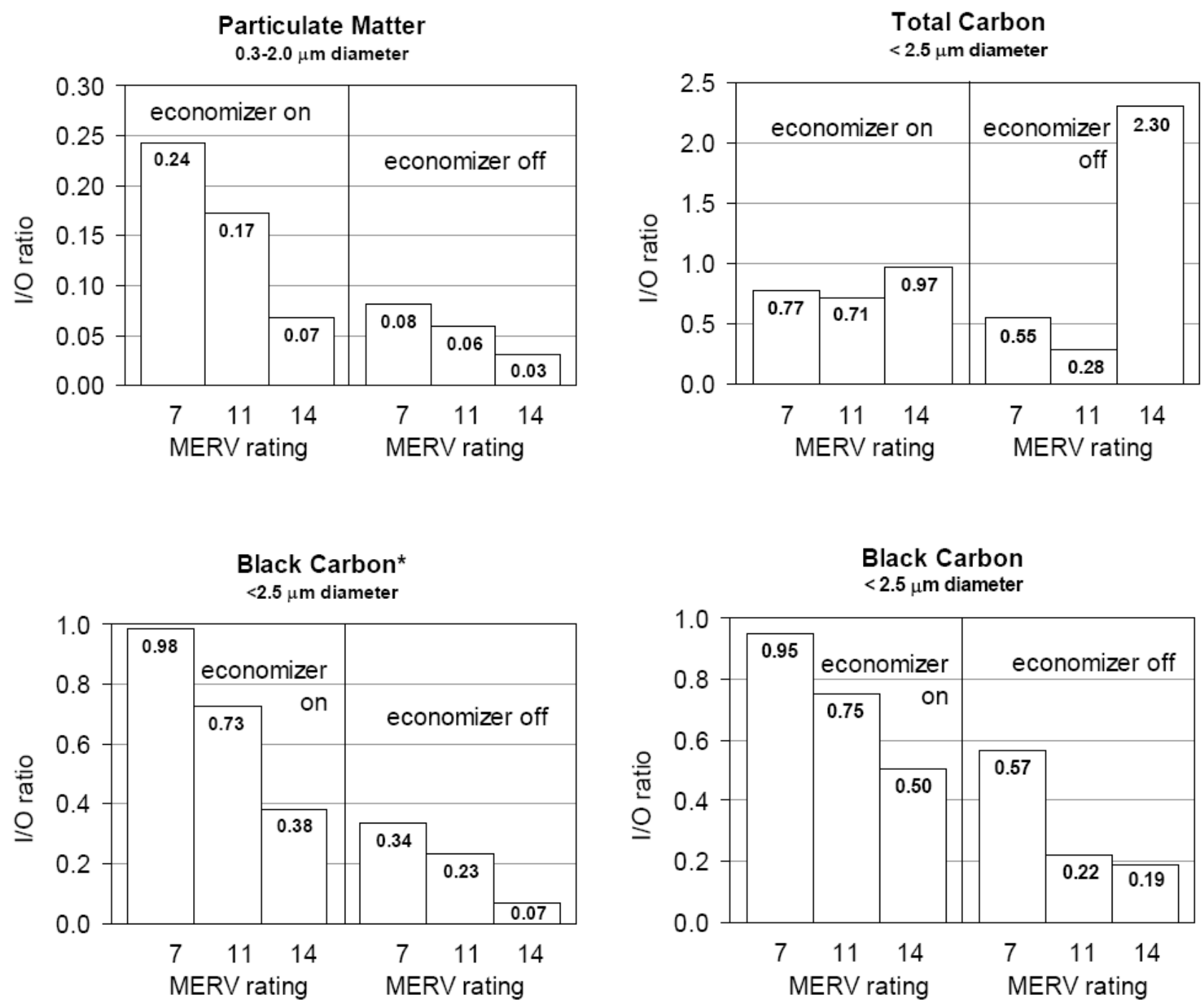
Figure 2
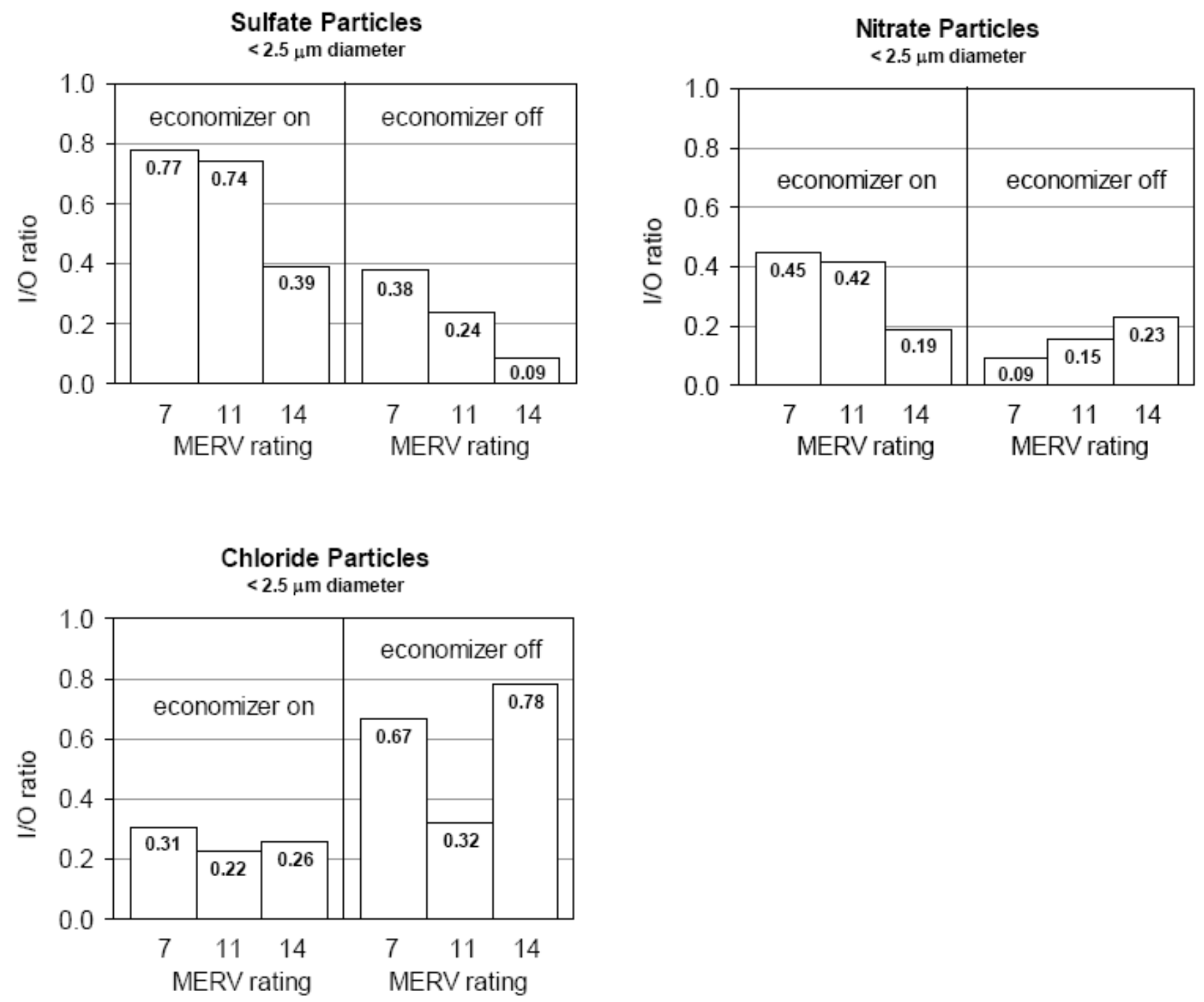


\section{Figure 3}
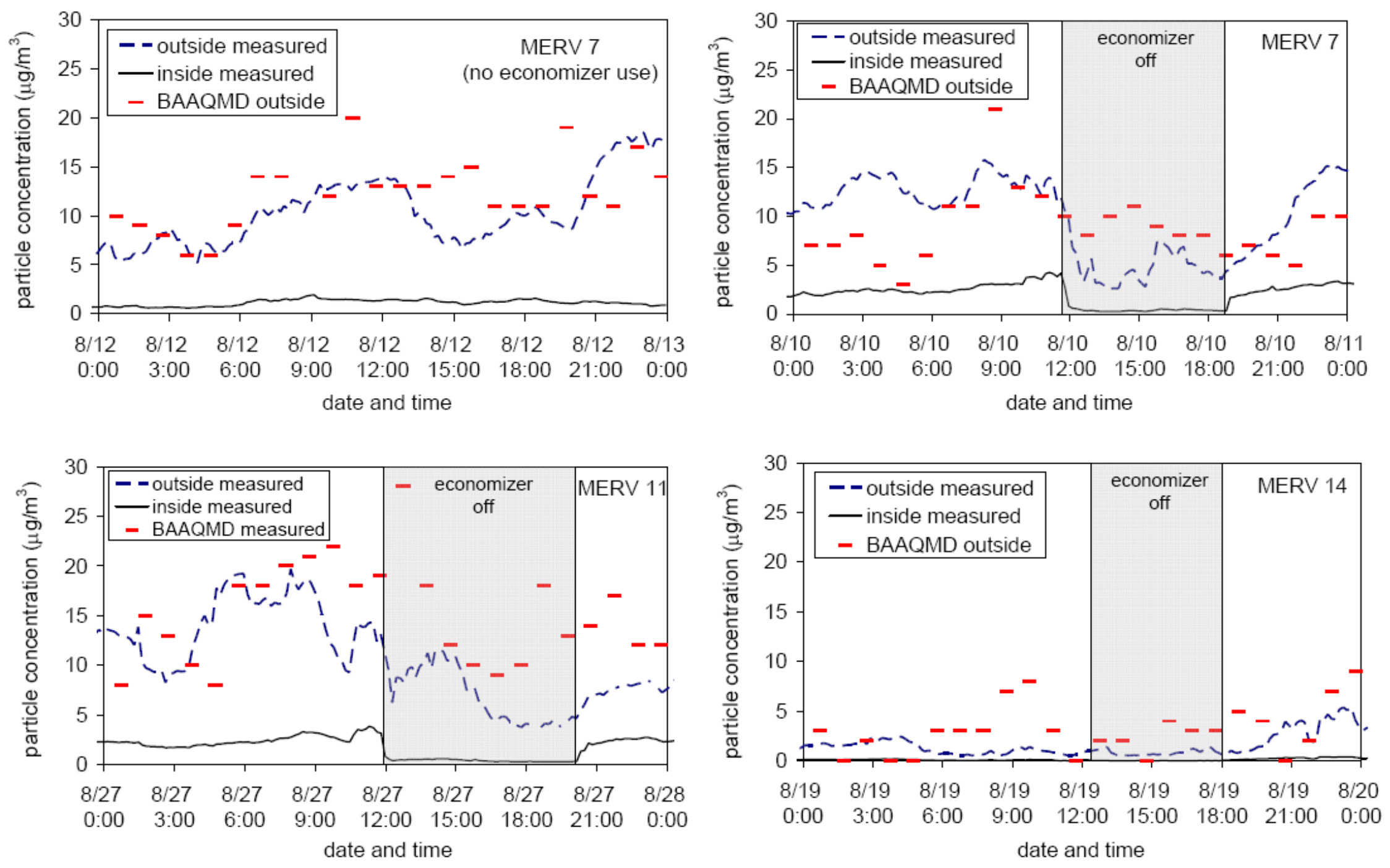
Figure 4
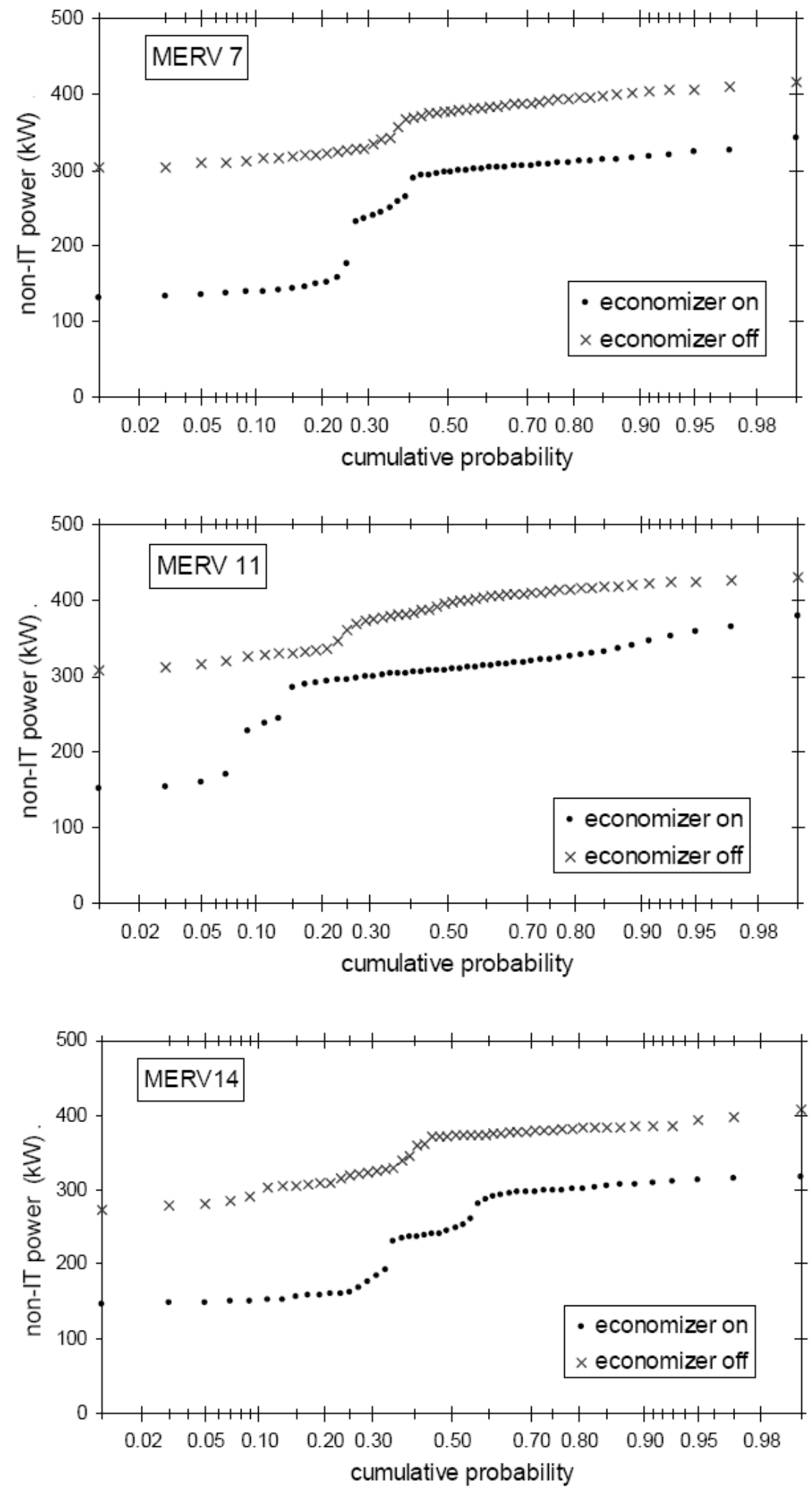